\title{
Adsorption of copper ions of natural montmorillonite clay
}

\author{
Ludmila Pimneva, ${ }^{1, *}$ \\ ${ }^{1}$ Industrial University of Tyumen, Volodarskogo str. 28, Tyumen, 625001, Russia
}

\begin{abstract}
The prospects of montmorillonite clay using for the extraction of copper ions from natural and waste waters were determined. Specified chemical and phase composition of natural forms of the montmorillonite clay are shown in the article. Quantitative characteristics of adsorption process of copper ions, the statistical exchange capacity is 1,21 (298 K), $1,25(313 \mathrm{~K}), 1,43(333 \mathrm{~K})$. The authors have studied the balance of copper ions by the method of constructing the isotherms. The description of the adsorption process was carried out by the Langmuir, Freundlich and Temkin models. The calculations showed that the best data for the sorption described by Langmuir model. The nature of the interaction of copper ions with montmorillonite clay in natural form is presented. The calculated thermodynamic parameters of the adsorption process, the obtained values of the Gibbs energy have a negative sign -11,5 (298 K), -15,6 (313 K), $16,2(333 \mathrm{~K}) \mathrm{KJ} / \mathrm{mol}$, that corresponds to a sustainable consolidation of copper ions on the surface of the montmorillonite clay.
\end{abstract}

\section{Introduction}

An important task of our time is to clean polluted water from heavy metal ions. The annual flow of pollutants in all water bodies leads to the contamination of not only the hydrosphere, but also of bottom sediments and soils. Water is a mobile medium that promotes migration of contaminants, including heavy metals over long distances. Sources of release into the environment heavy metals are natural and anthropogenic factors. From the point of view of environmental protection represent a serious danger to the wastewater electroplating plants, containing ions of zinc, cadmium, copper, manganese, cobalt, nickel, iron, chromium $[1,2]$.

Natural and waste water is a complex heterogeneous system that contains dissolved, colloidal and suspended in water of inorganic and organic compounds. Monitoring of water resources in 2011 showed a significant increase in the natural water of copper ions [3]. In connection with this increased interest in the use of effective and safe technologies for treatment of natural and waste waters. The most simple and effective methods of purification of natural and waste waters are sorption.

A promising direction is the use of environmentally friendly sorbents based on natural materials of clay and silicates [4-6], which have a high ion exchange selectivity to various compounds, chemically resistant and mechanically strong.

\footnotetext{
* Corresponding author: 1.pimneva@mail.ru
} 
The aim of this work is to study ion-exchange properties kisztelinski montmorillonite clay to copper ions, determination of its sorption characteristics, and experimental confirmation of the viability of the sorbent for purification of natural and waste waters of industrial enterprises.

\section{Subjects and Methods}

As the sorbent used kisztelinski natural montmorillonite clay. The analysis of the chemical composition of the clay was determined by scanning electron microscope (SEM). According to the data obtained its main components include the oxides in the amounts given in Table 1.

Table 1. The chemical composition of the montmorillonite clay

\begin{tabular}{|l|c|c|c|c|c|c|c|c|}
\hline contents & $\mathrm{SiO}_{2}$ & $\mathrm{Al}_{2} \mathrm{O}_{3}$ & $\mathrm{Na}_{2} \mathrm{O}$ & $\mathrm{K}_{2} \mathrm{O}$ & $\mathrm{CaO}$ & $\mathrm{Fe}_{2} \mathrm{O}_{3}$ & $\mathrm{TiO}_{2}$ & $\mathrm{MgO}$ \\
\hline$\%$ mass. & 54.0 & 20.73 & 0.75 & 3.07 & 0.44 & 9.43 & 1.1 & 1.82 \\
\hline
\end{tabular}

The loss on ignition of natural kisztelinski montmorillonite clay are $8,66 \%$.

The results of chemical analysis show that the composition includes 54\% silicon dioxide and $20.73 \%$ of aluminum oxide that defines pawkily the nature of the clay. Watersoluble oxides of sodium and potassium in the amount of $3.82 \%$.

Chemical (Table 1) and phase composition (Fig. 1) natural montmorillonite clay kisztelinski confirmed the presence of $47 \%$ of montmorillonite, and the total proportion of clay minerals, taking account of kaolinite and chlorite is $69 \%$. Montmorillonite is a three layer silicate, in the crystal lattice which contains two tetrahedral layers of silicon dioxide, facing peaks to each other, between which the octahedral layer of aluminum oxide.

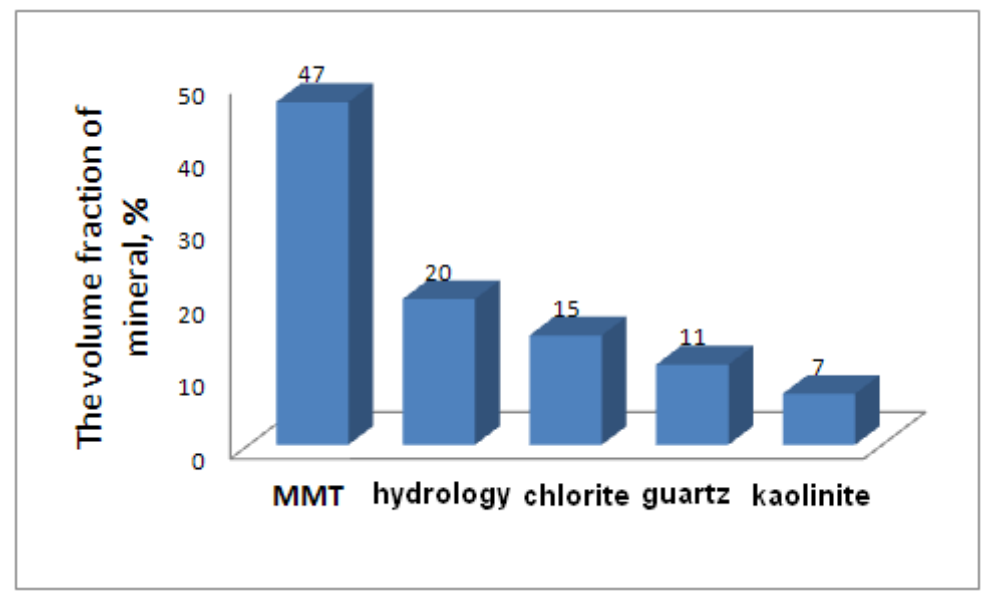

Fig. 1. The phase composition of the montmorillonite clay

Montmorillonite and chlorite are the crystal lattice of monoclinic crystal structure, which is movable due to the changing size of micropores and the widening of the unit cell [7]. An important feature of the mineral is ability to adsorb various cations and group ( $\equiv \mathrm{Si}$ $\mathrm{OH})$ determines the ability to ion exchange. As a result of adsorption and ion exchange parameter of the crystal cell can be increased from 4 to 20 that provides ease of penetration of the ions in interpackage space increasing the exchange capacity of montmorillonite to $150 \mathrm{mg}$-equivalent/100 г [8]. 
Figure 2 shows that the montmorillonite clay particles have sizes less than 1 micron in the form of thin leaves with irregular outlines.

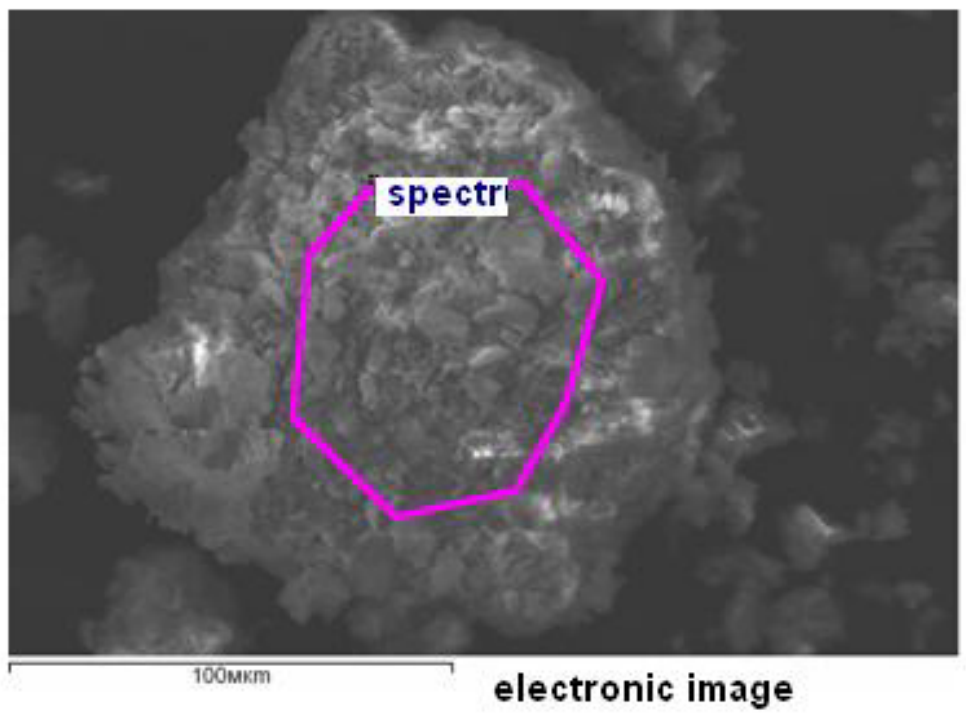

Fig. 2. SEM-micrograph

Study of the sorption capacity of montmorillonite clay in relation to cations of copper (II) was carried out in static conditions at temperatures $298,313,333 \mathrm{~K}$. The sorbent in the amount of $1 \mathrm{~g}$ was filled in $50 \mathrm{ml}$ of a solution of sulphate of copper. The solutions were prepared by the method of dilution of the copper sulfate solution with concentrations of copper ions from 0.02 to $1.4 \mathrm{mg} / \mathrm{ml}$. The contact of sorbent with solution is continued until the balance within 7 days. Then the sorbent and the solution was separated and analyzed for the content of copper ions and the $\mathrm{pH}$ measured. The concentration of copper cations in the solution was determined by chelatometric titration with Trilon $\mathrm{B}$ in the presence of the indicator murexide [9].

\section{Results}

The experimental results of the study constructed sorption isotherms of copper ions on montmorillonite clay, shown at figure 3. The form of sorption isotherms according to the BET classification [10] corresponds to 1 type. The form of the isotherms indicates the degree of affinity of the ions to the sorbent. Isotherm of type 1 reflects the monomolecular adsorption. For izoterma sorption is determined by the maximum exchange capacity of the sorbent is calculated and the selected energy characteristics of the process.

Quantitative description of the equilibrium sorption of copper ions on natural sorbent was used the model of Langmuir, Freundlich and Temkin in the table 2. The surface of the sorbent in the model of Langmuir is limited. The sorption saturation of the surface of the sorbent increases with increasing concentration [8]. 


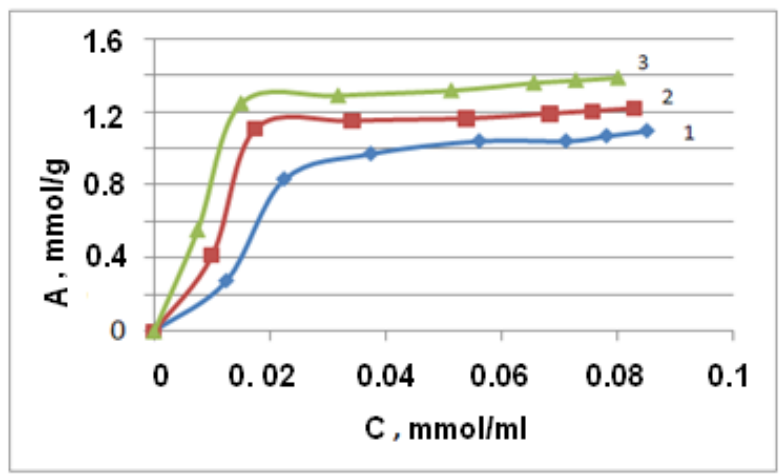

Fig. 3. Izotermy sorption of copper ions on montmorillonite clay at a Temperature, K: 298(1), 313(2), 333(3)

Model Freundlich isotherm used to describe adsorption on heterogeneous surfaces. The sorption centers by this model have different values of energy, so in the first place is filling the active centers with the maximum value of the energy [11]. A model of the Temkin isotherm assumes that heat of adsorption of the molecules in the layer decreases linearly as the filling layer due to the repulsion of metal ions. The decrease in heat of adsorption occurs according to a linear law [12].

Table 2. Models Langmuir, Frendlich and Temkin isotherms to describe sorption

\begin{tabular}{|c|c|c|}
\hline Модель & Уравнение & Линейная форма \\
\hline Langmuir & $A=A_{\infty} \frac{k_{L} \cdot C_{P}}{1+k_{L} \cdot C_{P}}$ & $\frac{C_{P}}{A}=\frac{C_{P}}{A_{\infty}}+\frac{1}{A_{\infty} \cdot k_{L}}$ \\
\hline Frendlich & $A=k_{F} C_{P}^{1 / n}$ & $\lg A=\lg k_{F}+\frac{1}{n} \cdot \lg C_{P}$ \\
\hline Temkin & $A=\frac{1}{\propto} \cdot \ln \left(k_{T} \cdot C_{P}\right)$ & $A=\frac{1}{\propto} \cdot \ln k_{T}+\frac{1}{\propto} \cdot \ln C_{P}$ \\
\hline
\end{tabular}

where $A$ - is the number sorbirovannoe copper and $A_{\infty}$ - the value of limiting sorption $(\mathrm{mmol} / \mathrm{g}), C_{P}$ - equilibrium concentration of copper ions in solution $(\mathrm{mmol} / \mathrm{ml}), k_{L}$ concentration the sorption equilibrium constant, characterizing the intensity of sorption, $\mathrm{ml} / \mathrm{mmol} ; k_{F}$ - the Freundlich constant, sorption capacity corresponding, $n$ - the Freundlich constant indicating intensity of the adsorption; $k_{T}$ - the constant of the sorption equilibrium, $\propto$ - constant characterizing the heat of adsorption.

Linear processing of isotherms of sorption of copper ions from aqueous solutions on montmorillonite clay are presented in Table 3.

Table 3. Values of the sorption parameters for sorption of copper ions, calculated using the linear form of the equations of Langmuir, Freundlich and Temkin

\begin{tabular}{|c|c|c|c|}
\hline \multicolumn{4}{|c|}{ The Langmuir Model } \\
\hline $\mathrm{T}, \mathrm{K}$ & $\Gamma_{\infty}, \mathrm{mmol} / \mathrm{g}$ & $k_{L}$, & $R^{2}$ \\
\hline 298 & 1.21 & 103 & 0.998 \\
\hline 313 & 1.25 & 400 & 0.999 \\
\hline 333 & 1.43 & 350 & 0.999 \\
\hline \multicolumn{4}{|c|}{ Model Freundlich } \\
\hline $\mathrm{T}, \mathrm{K}$ & $k_{F}$ & $n$ & $R^{2}$ \\
\hline 298 & 6.62 & 1.38 & 0.886 \\
\hline 313 & 1.66 & 7.30 & 0.817 \\
\hline 333 & 1.55 & 8.93 & 0.995 \\
\hline
\end{tabular}




\begin{tabular}{|l|ll|l|l|}
\hline \multicolumn{7}{|c|}{ Model Temkin } \\
\hline \multicolumn{7}{|c|}{$\mathrm{T}, \mathrm{K}$} & $k_{T}$ & \multicolumn{1}{c|}{$\propto$} & $R^{2}$ \\
\hline 298 & 5.13 & 2.24 & 0.995 \\
\hline 313 & 1.99 & 5.29 & 0.951 \\
\hline 333 & 1.74 & 6.58 & 0.943 \\
\hline
\end{tabular}

The values of correlation coefficients $\left(R^{2}\right)$ in table 3 show that the sorption of copper ions on montmorillonite clay with maximum probability is described by the Langmuir equation. The calculation results confirm that the sorption of copper ions on montmorillonite clay maximum sorption $A_{\infty}$ is equal to $1.21 \mathrm{mmol} / \mathrm{g}$, and the sorption equilibrium constant equals $103.0 \mathrm{ml} / \mathrm{mmol}(298 \mathrm{~K})$, which characterizes the energy of interaction of copper ions with the surface of the sorbent.

The maximum capacity of the montmorillonite natural clay with temperature increases on copper ions is $1.21(298 \mathrm{~K}) ; 1,25(313 \mathrm{~K})$ and $1.43(333 \mathrm{~K})$. The values obtained are higher than when the copper sorption on natural kaolinite [13]. This is because sorption of copper ions on montmorillonite clay occurs in three forms: in the form of vnutrismennyh complexes (specific adsorption), in the form of outer-sphere complexes (nonspecific adsorption) and in a diffuse layer [5]. In the formation of outer-sphere complexes between copper ions and the surface of the sorbent are water molecules that prevent the formation of covalent bonds. This type of interactions determine the reactions of ion exchange, which significantly increases the value of the maximum adsorption.

The value of the constant $\mathrm{n}$ in the Freundlich equation is greater than 1, which indicates favorable conditions associated with a decrease of the binding energy of the sorbent - sorbate as you fill the surface. The value of the constant $k_{F}$ confirms the ease of transport of copper ions sorbed from solution in the phase sorbent.

Different values of adsorption at different temperatures allows the calculation of thermodynamic characteristics of adsorption: the enthalpy change $(\Delta \mathrm{H})$, entropy $(\Delta \mathrm{S})$ and Gibbs energy $(\Delta \mathrm{G})$, suggesting the sorption mechanism. The calculation $\Delta \mathrm{H}$ was performed using equations isostere in the integral form. The results are shown in Fig. 4, which show that with increasing concentration of copper ions in the solution begins to sharply decrease $\Delta \mathrm{H}$.

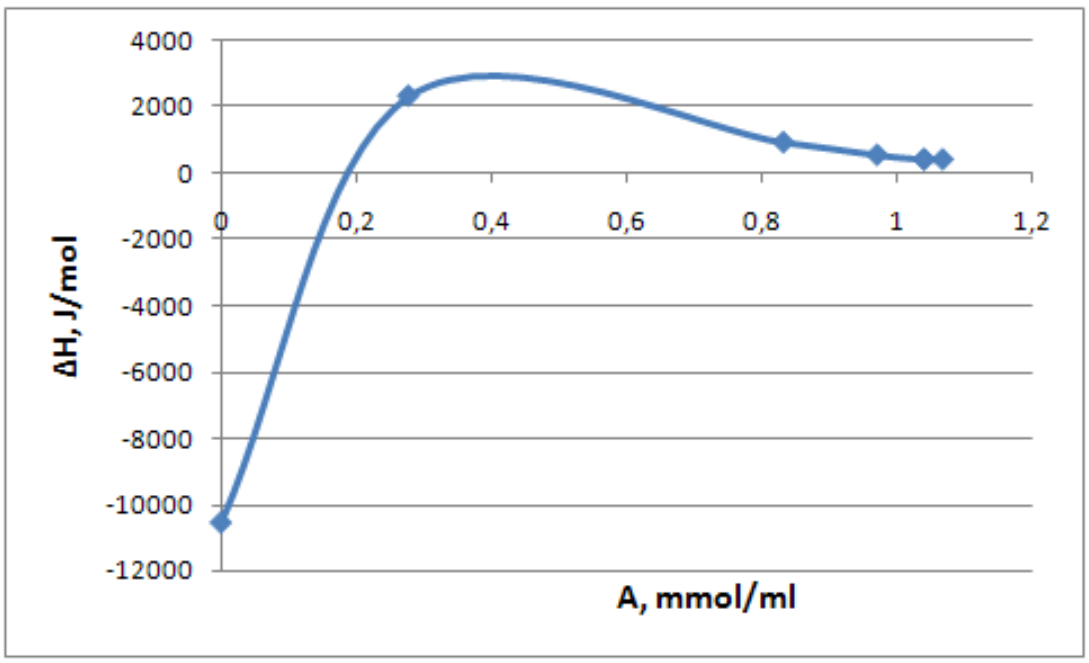

Figure 4. The change of enthalpy of sorption of ions of copper (II) from the value of the sorption on the montmorillonite clay kisztelinski 
This is because in the region of small concentrations of copper ions adsorbed on the active sites of the surface of the montmorillonite clay, accompanied by an increase in enthalpy. Filling of less active centers is accompanied by a decrease in enthalpy.

The Gibbs free energy $\Delta \mathrm{G}$ were determined according to the equation [14]:

$$
\Delta \mathrm{G}=-\mathrm{R} \cdot \mathrm{T} \cdot \ln \mathrm{K}_{\mathrm{L}}
$$

where $\Delta \mathrm{G}$ - Gibbs energy, $\mathrm{J} / \mathrm{mol} ; \mathrm{R}$ - the molar gas constant, $\mathrm{J} / \mathrm{mol} \cdot \mathrm{K} ; \mathrm{T}$ - temperature, $\mathrm{K}$; $\mathrm{K}_{\mathrm{L}}$ - equilibrium constant. The results of calculation of thermodynamic parameters of adsorption are given in table 4.

Table 4. Thermodynamic parameters of adsorption of copper ions on montmorillonite clay

\begin{tabular}{|l|c|c|c|}
\hline thermodynamic parameter & $\mathrm{T}=298 \mathrm{~K}$ & $\mathrm{~T}=313 \mathrm{~K}$ & $\mathrm{~T}=333 \mathrm{~K}$ \\
\hline$A_{\max }, \mathrm{mmol} / \mathrm{ml}$ & 1.21 & 1.25 & 1.43 \\
\hline$\Delta \mathrm{G}, \mathrm{kJ} / \mathrm{mol}$ & -11.5 & -15.6 & -16.2 \\
\hline$\Delta \mathrm{S}, \mathrm{J} / \mathrm{mol} \cdot \mathrm{K}$ & \multicolumn{3}{|c|}{3.28} \\
\hline$\Delta \mathrm{H}, \mathrm{kJ} / \mathrm{mol}$ & \multicolumn{3}{|c|}{-10.5} \\
\hline
\end{tabular}

The value of the enthalpy $(\Delta \mathrm{H})$ confirms the physical adsorption of copper ions on natural montmorillonite clay. The values of Gibbs energy indicates a spontaneous process of adsorption and stable fixation of copper ions on the surface of montmorillonite clay [15]

\section{Conclusions}

On the basis of their studies of the adsorption process of copper ions on natural montmorillonite clay were installed the high efficiency of extraction of ions from aqueous solutions. It is established that the isotherm sorption of $\mathrm{Cu}^{2+}$ in a wide interval of concentrations of the solution $\mathrm{CuSO}_{4}$ described by the Langmuir equation. A thermodynamic analysis of the adsorption of copper ions, which confirms the mechanism of physical adsorption.

\section{References}

[1] Yu. I. Tarasevich, Natural sorbents in water treatment processes, Kiev, Naukova Dumka, 1981.

[2] G.Parfit, K. Rochester, Adsorbtion from solutions on solid surfaces: translation from English, Publishing house Mir, Moscow, 1986.

[3] Report on the scientific study № 11.G34.31.0036 from 25.11.2010 г. "The water quality in conditions of anthropogenic loads and climate change and the regions of Western Siberia", Tyumen: TGU, 2012.

[4] E.S. Klimov, M.V. Busaeva, Natural sorbents and chelating agents in wastewater treatment, Ulyanovsk, UGTU, 2011.

[5] T.A. Sokolova, S. Trofimov, Sorption properties of soils, Adsorption, Cation exchange, textbook, Tula, 2009.

[6] G.I. Zubareva, A.V. Gurinovich, M.I. Degtev, Methods of purification of waste waters from cations of heavy metals, Ecology and industry of Russia, 2008.

[7] A.G. BetechTin, The crystallography course, Moskow, 2007.

[8] V.M. Besruk, Strengthening of soils in road and airfield construction, Transport, Moskow, 1971.

[9] L.A. Pimneva, Regularities of sorption of copper cations (II) by kaolinite, International journal of applied and fundamental research, 2015. 
[10] S Greg, K. Sing, Adsorption, specific surface, porosity: translation from Englich, Publishing house Mir, Moskow, 1984.

[11] S.S Voski, Course of colloid chemistry, Chemistry, Moskow, 1976.

[12] Yu.G. Frolov, Course of colloid chemistry, Surface phenomena and disperse systems Moskow, 2004.

[13] L. Pimneva, E. Malyshkina, E. Salnikova Regularities of sorption of cations of zinc and copper by natural sorbent, Procedia Engineering, 2016.

[14] Yu.G. Frolov, Surface phenomena and disperse systems, Chemistry, Moskow, 1982.

[15] L.A. Pimneva, A.V. Kazantseva, Study of the adsorption of manganese ions by natural kaolinite, Modern high technologies, 2016. 